\title{
JUAN DUNS ESCOTO: CUESTIONES SOBRE LAS CATEGORÍAS DE ARISTÓTELES, QQ. 1-3
}

\author{
Héctor Hernando Salinas LeaL* \\ doi:10.11144/Javeriana.uph33-67.tcca
}

\section{RESUMEN}

Ofrecemos la primera traducción castellana de las primeras tres cuestiones del comentario de Juan Duns Escoto a las Categorías de Aristóteles. En ellas, el franciscano distingue el subiectum del tratado aristotélico bajo el concepto lógico de «categoría», fundando la unidad de su tratamiento sobre la unidad de dicho concepto. Para tal efecto, Escoto distingue el estudio propiamente lógico de las categorías, tanto de su estudio lingüístico (que se funda en la expresión del pensamiento en el lenguaje), como de su estudio por parte del metafísico (en el que prima la diversidad categorial), al menos en esta primera etapa de su pensamiento.

Palabras clave: Juan Duns Escoto; Aristóteles; categorías; lógica medieval; metafísica medieval

* Pontificia Universidad Javeriana, Bogotá, Colombia.

Correo electrónico: hsalinas@javeriana.edu.co

La presente traducción al castellano, procede de la edición crítica: IoANnis Duns Scoti. (1999). Questiones In Librum Porphyrii Isagoge et Quaestiones Super Praedicamenta Aristotelis. R. Andrews et al. (Eds.), Opera philosophica I (pp. 249-271). St. Bonaventure, New York: The Franciscan Institute.

Para citar este artículo: Salinas Leal, H. H. (2016). Juan Duns Escoto: Cuestiones sobre las Categorias de Aristóteles, QQ. 1-3. Universitas Philosophica, 33(67), pp. 275-302. ISSN 0120-5323, ISSN en línea: 2346-2426, doi:10.11144/Javeriana.uph33-67.ldvs

Esta traducción es uno de los resultados del proyecto de investigación 006268 Juan Duns Escoto antes de la univocidad del ser, inscrito en la Vicerrectoría de Investigación de la Pontificia Universidad Javeriana, Bogotá. La cátedra sobre Duns Escoto que tuve a mi cargo durante el primer semestre de 2014 y el primer semestre de 2015 en la carrera de filosofía de la Universidad Javeriana, me permitió preparar y ofrecer a los estudiantes una primera versión fragmentaria de estas cuestiones. Por último, el par académico que evaluó esta traducción para su publicación me permitió también mejorar muchos aspectos de la misma. A él o ella, mi especial agradecimiento. No deja de caer sobre mis hombros cualquier falla, grande o pequeña, que aún subsista en el texto. 


\title{
JOHN DUNS SCOTUS: QUESTIONS ON ARISTOTLE'S CATEGORIES, QQ. 1-3
}

\author{
Héctor Hernando Salinas Leal
}

\begin{abstract}
This is the first Spanish translation of the three first questions, of Scotus's commentary on Aristotle's Categories. The Franciscan distinguishes the subject matter of the Aristotelian treatise under the logical concept of «category», grounding the unity of their treatment as a scientific object on the unity of this concept. To do so, Scotus distinguishes the properly logic study of categories, from its linguistic treatment (which grounds in their utterance) and from the metaphysician's study (where its real diversity is considered), al least in this first moment of his thought.

Key words: John Duns Scotus; Aristotle; categories; medieval logic; medieval metaphysics
\end{abstract}




\section{Presentación del traductor}

LA TRADICIÓn FILOSÓFICA RECONOCE EN Juan Duns Escoto al filósofo de la univocidad del ser. En efecto, en el primer libro de su Ordinatio, comentario al libro de las Sentencias de Pedro Lombardo, al preguntarse en la distinción tercera, en el conjunto que forman las cuestiones primera y segunda, «si Dios es naturalmente cognoscible por el intelecto del viador»y «si Dios es el primer conocido por nosotros naturalmente en el estado de la vida presente» (Ord. I, d. 3, qq. 1-2, nn. 1 y 6, edición Vaticana, III, p. 1-3), Escoto formula como parte de su respuesta la tesis conforme a la cual el concepto de ser es unívoco a Dios y las criaturas, es decir, a todo lo real. Esta tesis comporta una verdadera revolución en la historia de la metafísica, pues supone la primera solución univocista a la problemática aristótelica de los múltiples sentidos del ser y, a partir de ella, abre la posibilidad de fundar la metafísica como ciencia, según los parámetros de los Segundos Analiticos.

Sin embargo, en su obra temprana, de la que forman parte sus comentarios a las obras lógicas de Aristóteles, Escoto rechaza tanto la univocidad como la analogía del concepto de ser considerado desde un punto de vista lógico, dejando lugar a la tesis de su equivocidad lógica sobre el fondo de la analogía real entre los seres. Esta refutación tiene lugar en la cuestión 4 de sus Cuestiones sobre las Categorías de Aristóteles. Además de esta refutación de la univocidad y de la analogía lógicas del concepto de ser, este comentario ofrece una aproximación a la determinación de subiectum del tratado de las Categorías, es decir de su campo de conocimiento científico, y al problema de la naturaleza (¿ontológica, lógica o lingüística?) de las categorías aristotélicas. La pregunta por el subiectum del tratado debe entenderse desde las exigencias que los Segundos Analíticos imponen a algo para que pueda cumplir el papel de «objeto» de un saber científico. La presuposición que guía el comentario es, en efecto, que el tratado de las Categorías es un tratado científico que se ocupa del estudio de una parte de la ciencia lógica: el concepto de «categoría en general».

En la presente traducción ofrecemos al lector de lengua castellana las tres primeras cuestiones de este comentario. En ellas, Escoto introduce las condiciones teóricas que explicarán su rechazo de la univocidad y de la analogía lógicas del ser. 
En la primera cuestión (¿El libro de las Categorias se ocupa de las diez voces que significan los diez géneros de las cosas?) se distinguen las dimensiones lingüística y conceptual o intencional del pensamiento. La dimensión lingüística se funda en la expresión del pensamiento en el lenguaje hablado o escrito. Sin embargo, el tratado de las Categorías se sitúa en la dimensión del pensamiento mismo, en su autonomía y anterioridad con respecto a su expresión en el lenguaje. Así, el primer paso en estas cuestiones consiste en distinguir, para decirlo con toda simplicidad, lenguaje y pensamiento, dándole una anterioridad natural a este último.

Con esta primera distinción ganada, en la segunda cuestión (¿El libro de las Categorías se ocupa de las diez categorías como de su sujeto?) se distinguen dos enfoques en el tratamiento de las categorías. Desde la lógica se estudian las categorías «en cuanto se les atribuye algo causado por la razón» (q. 2, n. 19) y desde la metafísica se estudian en tanto son (q. 2, n. 24). En el contexto del comentario, las categorías se estudian desde el punto de vista lógico y, por lo tanto, es la causalidad de la razón la que funda la consideración de la ciencia lógica de las categorías.

En la tercera cuestión (¿Algún predicado intencional es unívoco a las diez categorías?), sobre la distinción ganada en la cuestión anterior, se distiguen la diversidad real de las categorías y su unidad de atribución en la sustancia, de las que se ocupa el metafísico, y la unidad que el intelecto causa y bajo la cual considera las categorías según un único modo de concebirlas (modus concipiendi), que corresponde a la preocupación del lógico. En esta tercera cuestión, Escoto distingue entre lo concebido por el intelecto y el modo de concebirlo. La unidad intencional o lógica se funda sobre el modo de concebir y no sobre lo concebido.

No sobra subrayar que las Cuestiones sobre las Categorías de Aristóteles de Escoto mantienen una doble relación con el texto aristotélico de las Categorías. De un lado, exhiben un conocimiento profundo de su contenido y de sus implicaciones filosóficas y en ese sentido dependen estrechamente de él pero, de otro lado, no se presentan como un comentario literal que tiene por fin explicar el texto aristotélico. Las Cuestiones buscan plantear problemas filosóficos actuales cuyo planteamiento se deriva de una lectura de las Categorias. Las Cuestiones escotistas, como verá el lector, están menos en función de explicar a Aristóteles que de pensar con él y a partir de él; son un ejemplo de la evolución medieval del comentario filosófico que a esta altura ya no se preocupa por explicar o interpretar una obra en símisma. 
Estas cuestiones comportan una novedad fundamental no solo de interpretación del texto aristotélico sino frente a él: en ellas se introduce el tratamiento del concepto lógico de «categoría en general». Este permite fundar y justificar, en su unidad intencional, la ciencia lógica de las categorías, frente a la metafísica de las categorías y a la expresión lingüística de las categorías, tanto en su dimensión lógica como metafísica. En ese sentido, la lógica de las categorías, es una lógica sobre el concepto de categoría y no sobre la diversidad categorial. Por lo demás, sobre este telón de fondo se construirá la refutación de la univocidad y la analogía lógicas del concepto de ser en la cuarta cuestión del mismo comentario. Sin embargo, ese último texto y sus consecuencias se dejarán para una reflexión y una traducción posteriores.

Para la traducción, he seguido el texto crítico del comentario: Ioannis Duns Scoti, Questiones In Librum Porphyrii Isagoge et Quaestiones Super Praedicamenta Aristotelis, eds. R. Andrews et al., Opera philosophica I, St. Bonaventure (NY), The Franciscan Institute, 1999, pp. 249-271. Para la división del texto, he seguido la numeración de los parágrafos y los títulos propuestos por esta edición crítica. Por lo demás, hoy día solo se cuenta con una traducción completa al inglés: John Duns Scotus, Questions on Aristotle's Categories, (trad. Lloyd A. Newton), Washington, The Catholic University of America Press, 2014.

Los comentarios de Escoto a Aristóteles se citan según el autor, el título de la obra, la cuestión, el parágrafo, la edición, el volumen y la página. Por ejemplo, el Comentario a las Categorías, cuestión 2, parágrafo 10, en las Opera Philosophica, volumen I, página 260 se cita así: Duns Scotus, In Praed., q. 2 n. 10 (OPh, I, 260).

Como el lector ya lo ha podido constatar, opto por traducir el término latino subiectum por el español sujeto y no por objeto. El subiectum scientiae corresponde al dominio que delimita una ciencia y le da unidad, y en efecto podría corresponder a lo que hoy llamamos el objeto de una ciencia. Sin embargo, Escoto utiliza sistemáticamente el término subiectum para referirse al sujeto de una ciencia, ocasionalmente utiliza el término obiectum para referirse a aquello sobre lo que recae una capacidad o potencia, por ejemplo, el objeto del intelecto. Aquí encontramos un caso en la cuestión 3, parágrafo 13. Esto no excluye que haya pasajes en la obra de Escoto en los que parece usar simultánea e indistintamente tanto subiectum como obiectum para referirse al sujeto de una ciencia. Por ejemplo en su comentario 
a la Metafisica de Aristóteles: Duns Scotus, In Met., I, Prol. n. 32 (OPh, III, 14) y In Met., I, q. 1 (OPh, III, 15).

Las notas a pie de página se han utilizado de dos modos. Unas son extraídas del aparato de fuentes de la edición crítica. En estas se ofrece el texto latino y su traducción castellana. Para ello, he revisado, en cuanto ha sido posible, las ediciones críticas disponibles de esos textos y, salvo indicación contraria, las traducciones del aparato de fuentes también son mías. Además, hay notas que corresponden propiamente a aclaraciones de mi parte. Estas se identificarán con la descripción «(N. del T.)». Finalmente, utilizo ocasionalmente los corchetes, [ ], para explicitar sujetos tácitos y otras expresiones que son supuestas en la escritura escotista de modo que la lectura sea un poco menos tortuosa y gane algo en claridad.

\section{Q. 1: ¿El libro de las Categorías se ocupa de las diez voces que significan los diez géneros de las cosas?}

\section{SE LLAMAN EQUÍVOCOS ETC ${ }^{I}$.}

Se PREgunta Si el Libro de las Categorías se ocupa de las diez voces que significan los diez géneros de cosas.

1 Esta es una cita de las primeras líneas del tratado de las Categorías en las que Aristóteles define las realidades equívocas, unívocas y denominativas. Aristóteles, Praedicamenta, c. 1, 1a1, 1a7, 1a13 (AL, $\left.\mathrm{I}^{2}, 47\right)$ : «Aequivoca dicuntur quorum solum nomen commune est, ratio autem substantiae est diversa, ut animal homo et quod pingitur. (...) Univoca vero dicuntur quorum et nomen commune est et secundum nomen eadem substantiae ratio, ut animal homo atque bos. (...) Denominativa vero dicuntur quaecumque ab aliquo, solo differentia casu, secundum nomen habent appellationem, ut a grammatica grammaticus et a fortitudine fortis». «Se llaman homónimas las cosas cuyo nombre es lo único que tienen en común mientras el correspondiente enunciado de la entidad es distinto, v.g.: vivo dicho del hombre y dicho del retrato. (...) Se llaman sinónimas las cosas cuyo nombre es común y cuyo correspondiente enunciado de la entidad es el mismo, v.g. vivo dicho del hombre y dicho del buey. (...) Se llaman parónimas todas las cosas que reciben su denominación a partir de algo, con una diferencia en la inflexión, v.g.: el gramático a partir de la gramática, y el valiente a partir de la valentía » (Trad. del griego, Candel Sanmartín, p. 29-30).

Cabe aclarar desde ahora, que en este trabajo siempre damos la referencia y citamos el texto latino de Aristóteles, así como el texto latino de la Isagoge de Porfirio, que consultamos en las ediciones críticas del Aristoteles Latinus. Así, en esta misma nota, el paréntesis de la referencia se lee del siguiente modo: Aristoteles Latinus, volumen I, facsímil 2, página 47. Ver las referencias bibliográficas del final. (N. del T.) 


\section{1-5 ARGUMENTOS A FAVOR}

1. Al parecer sí.

Porque así lo dice Boecio² .

2. Asimismo, este tratado determina sobre lo unívoco, lo equívoco y lo denominativo, que únicamente son diferencias de la voz significante (vocis significantis), puesto que ninguna cosa y ningún concepto son equívocos, porque allí donde se encuentra el mismo concepto, allí hay univocación.

3. Asimismo, todas ellas se definen por "se dicen".

4. En la primera división, el texto dice "de aquellos que se dicen" ${ }^{4}$. Del mismo modo, más abajo el texto dice "de los singulares no-complejos (singulum incomplexorum) o significa la substancia" ${ }^{5}$, etcétera. Sin embargo, significar un decible no-complejo (decibile incomplexum) es propio de la voz significante (vocis significantis); por lo tanto, ella es su sujeto. Y así, serán su sujeto en grado sumo las diez voces que significan los diez géneros, pues solo se trata de ellas en este tratado.

5. Asimismo, o la lógica es una ciencia real o es una ciencia del discurso (scientia sermocinalis). Y es evidente que no es una ciencia real. Por lo tanto, es una ciencia del discurso. Por lo tanto, cualquiera de sus partes trata sobre la voz significativa (de voce significativa). Y así, esta parte, la primera, se ocupará de la voz que significa el concepto simple, como el libro Sobre la Interpretación se ocupa de la voz que significa el concepto compuesto.

2 Boecio, In Categorias Aristotelis, I (PL 64, 160 A-B): «Est igitur huius operis intentio de vocibus res significantibus, in eo quod significantes sunt prertractare... sitque in praesens praedicamentorum intentio, de primis vocibus significantibus prima rerum genera, in eo quod significantes sunt disputare». «Por lo tanto, la intención de esta obra es tratar de las voces que significan las cosas, en tanto las significan... aquí la intención del [tratado] de las Categorias es sostener que trata de las primeras voces que significan los primeros géneros de las cosas, en tanto las significan». Las cursivas son del traductor.

3 Aristóteles, Praedicamenta, c. 1, 1a 1, 1a 7, 1a 13 (AL, I' $\left.\mathrm{I}^{2}, 47\right)$.

4 Aristóteles, Praedicamenta, c. 2, 1a $16\left(\mathrm{AL}, \mathrm{I}^{2}, 47\right)$.

5 Aristóteles, Praedicamenta, c. 2, 1 b 25-26 (AL, $\left.\mathrm{I}^{2}, 48\right)$ : «Eorum quae secundum nullam complexionem dicuntur singulum aut substantiam significant aut quantitatem...». «Cada una de las cosas que se dicen fuera de toda combinación, o bien significa una entidad, o bien un cuanto...» (Trad. del griego, Candel Sanmartín, p. 33). 


\section{6-10 ARguMENTOS EN CONTRA (POSICIÓN DE ESCOTO)}

6. A favor de la posición opuesta, Boecio ${ }^{6}$ afirma que "la lógica se ocupa de las intenciones segundas aplicadas a las primeras [intenciones]"; por lo tanto, ninguna parte de la lógica se ocupa de las voces.

7. Aquello de lo que aquí se trata es por sí parte del sujeto (pars subiecti) considerado en el libro Sobre la interpretación, y es una parte de aquello considerado [como sujeto] en el libro de los Primeros Analíticos: el silogismo; pero, como es manifiesto, todas las propiedades del silogismo se encuentran en él y no en una voz existente, lo que tampoco es posible. Del mismo modo, el enunciado (enuntiatio) posee sus propiedades. Por lo tanto, el silogismo y el enunciado son naturalmente anteriores a la voz significativa. Y lo que se considera aquí es naturalmente anterior al uno y a la otra, como una parte integral [es anterior] al todo; por lo tanto, lo que se considera aquí primera y naturalmente es anterior a toda voz significativa. Por lo tanto, , la voz significativa no es el sujeto de este tratado.

8. Asimismo, en este tratado no se demuestra ninguna propiedad de la voz significativa, ni en ninguna otra parte de la lógica. Por lo tanto, etcétera.

9. Contra estos dos argumentos (nn. 7-8) se puede decir que "poseer tres términos" es una propiedad del silogismo en tanto se da en la voz, como "significar lo verdadero o lo falso" es una propiedad del enunciado y como ocurre con las otras propiedades del mismo tipo.

10. Contra este argumento: o el silogismo en la mente es un silogismo y el enunciado en la mente es un enunciado, o no. Si sí, de esto se sigue que poseen los atributos del silogismo y del enunciado sin que ellos sean proferidos. Si no, de allí se sigue que quien tiene la demostración en la mente no tiene la demostración a menos que la profiera; y no sabe, si no la profiere. Y esto es evidentemente falso.

6 No es una afirmación de Boecio, sino de Avicena, Philosophia prima sive scientia divina, I, 2 (AvL, I, 10): «Subiectum vero logicae, sicut scisti, sunt intentiones intellectae secundo, quae apponuntur intentionibus intellectis primo, secundum hoc quod per eas pervenitur de cognito ad incognitum». «En efecto, el sujeto de la lógica, como lo aprendiste, son las intenciones inteligidas secundariamente, las cuales se aplican a las intenciones inteligidas primariamente, en tanto por ellas se va de lo conocido a lo desconocido». 


\section{SOLUCIóN}

11. Sobre la pregunta puede decirse que este libro no se ocupa de las diez voces como de su sujeto primero (ut de primo subiecto) - y ninguna parte de la lógica se ocupa de la voz, porque todas las propiedades (passiones) del silogismo ${ }^{7}$ y todas sus partes se hallan en él (sibi inesse) según el ser que tienen en la mente, aunque no sean proferidas, como es manifiesto inductivamente. Sin embargo, este libro [de las Categorias] se ocupa de algo anterior (est de aliquo priore), que con respecto a la voz significativa únicamente tiene la razón de significado.

\section{2-27 RESPUESTAS A LOS ARGUMENTOS PRINCIPALES}

12. En respuesta a la autoridad de Boecio (n. 1) puede decirse que él entiende un enunciado pasivo por uno activo (intelligit passivam per activam), así: "se ocupa de las diez voces que significan los diez géneros de las cosas", es decir, se ocupa de los diez géneros significados por las diez voces. De qué modo esto es verdadero se dirá en la solución de la siguiente cuestión ${ }^{8}$.

13. En respuesta al segundo argumento (n. 2) puede decirse que lo unívoco y lo denominativo son, en primer lugar, diferencias del predicado que por sí está en el concepto (inest conceptui), y no lo son, en primer lugar, de la voz significante. Sin embargo, [Aristóteles] determina lo equívoco a causa de su oposicion a lo unívoco: o porque lo equívoco equivocado es propio del concepto, aunque no el equívoco que equivoca; o porque es un concepto en cuanto es significado.

14. En respuesta al otro argumento (n. 3): [Aristóteles] dice "son llamados" para mostrar que no se les asignan verdaderas definiciones a estos equívocos etc. - pues la definición es por género y diferencia-, sino solamente una razón que expresa lo que se dice por el nombre.

15. En respuesta al otro argumento (n. 4), digo que en la segunda división Aristóteles afirma "de aquellos que son". Y así como de estas palabras no se sigue que el sujeto de este libro sea algo real a lo cual por sí le conviene

7 Duns Scotus, In Porph., q. 3 n. 20 (OPh, I, 16-17).

8 Ver: q. 2 n. 19-27. 
ser, así tampoco se sigue de aquí que el sujeto sea la voz a la cual le conviene por sí ser dicha. Por lo tanto, él dice "son llamados", es decir, "son concebidos". Y "son" se toma en la segunda división en el mismo sentido: son según la razón.

16. En respuesta al otro argumento sobre el [decible] no complejo (n. 4), digo que aquel conviene en primer lugar al concepto simple y, por consiguiente (ex consequenti), [conviene] a la voz significante. Por lo tanto, si aquí el sujeto es un [decible] no-complejo, con mayor razón se sostiene que sea un concepto antes que una voz.

17. Sobre "significa" (n. 4), digo que de ello no se sigue que el sujeto de este libro sea la palabra (littera), como tampoco lo quiere Boecio. La palabra, que se encuentra entre los cuatro que se enumeran al comienzo del tratado Sobre la interpretación ${ }^{9}$, únicamente es signo y no significado (signatum). Así, tampoco se sigue aquí que el sujeto sea la voz a partir de este [término] medio "significa", puesto que este es un medio muy común. En efecto, la propiedad (passio) significa la cosa. Sin embargo, se establece correctamente que aquí el sujeto es el concepto.

18. En respuesta al otro argumento (n. 5), digo que la lógica no es una ciencia real ni una ciencia sobre el discurso (sermocinalis), porque no considera ni el discurso (sermonem) ni las propiedades del discurso, ni su sujeto bajo la razón de discurso. Por el contrario, que esta división sea insuficiente se prueba así: el medio entre la cosa (rem) y el discurso (sermonem) o la voz es la propiedad [del intelecto]; por lo tanto, así como hay una ciencia por sí de las cosas y alguna ciencia por sí de las voces significativas, como la gramática o la retórica, que consideran las propiedades de la voz en tanto voz, a saber la coherencia (congruum) y la belleza (ornatum), así puede haber alguna ciencia del concepto por sí; esta es la lógica. Es por ello que debe llamarse ciencia racional, no solo porque se ejerza por la

9 Aristóteles, De Interpretatione, 1, 16a 3-8 (AL, $\left.\mathrm{II}^{1}, 5\right)$. Boecio, In de Interpretatione. Ed. secunda, (ed. Meisner, 20, 26-28): «2uare quattuor ista sunt: ut litterae quidem significent voces, voces vero intellectus, intellectus autem concipiant res». «Por ello son cuatro: para que las palabras escritas signifiquen las voces, las voces signifiquen los conceptos y los conceptos conciban las cosas». 
razón como cualquier ciencia, sino en cuanto se ocupa de los conceptos formados por el acto de la razón.

19. Si alguien dijera ${ }^{10}$ que la lógica es una ciencia del discurso (scientiam sermocinalem), como parece a partir de una interpretación nominal, hay que entender que la lógica concuerda mucho (multum convenit) con el discurso. Esto por dos razones: porque el concepto es el significado inmediato de la voz y la lógica se ocupa del concepto, y también porque las propiedades del concepto se hallan (insunt) en la voz significativa como la no-complejidad (incomplexio), la composición (complexio), significar lo verdadero o lo falso-, en tanto [se hallan en el] signo en virtud de la naturaleza del significado.

20. En respuesta a aquello (n. 9) que se trata al responder los argumentos a propósito de los términos y de "significar lo verdadero y lo falso", puede decirse que un término es lo mismo que la voz que significa un concepto simple (vox significans conceptum simplicem), y entonces solo hay silogismo a partir de tres términos cuando el silogismo es proferido. $\mathrm{O}$ puede decirse con mayor verdad que un término significa lo mismo que el concepto simple, porque ["término"] se tomó de la geometría hacia la lógica para significar lo indivisible en las proposiciones (in propositionibus), que puede existir en la mente (esse in mente); y entonces todo silogismo, tanto proferido como no proferido, se construye a partir de tres términos. -De modo semejante, "significar lo verdadero y lo falso" conviene al enunciado (enuntiationi), pero no en tanto la voz significa el concepto, sino en tanto el concepto significa la cosa.

10 Ver: William of Sherwood, Introductiones in logicam, prologus (ed. Lohr, p. 222): «Quasdam autem facit operationes, per quas deveniat in scientiam. Et de his est sermocinalis scientia». «[El lógico] lleva a cabo algunas operaciones, por las cuales se alcanza la ciencia. Y una ciencia del discurso se ocupa de ellas» (Robert Kilwardby, De Ortu Scientiarum, ed. Judy, XXXIV, n. 346, p. 122). «De operationibus humanis et earum effectibus est scientia practica sive operativa; et sermonibus autem et eorum effectibus, sermocinalis scientia sive logica, prout logica dicitur a logos quod est sermo». «La ciencia práctica o de las acciones se ocupa de las acciones humanas y de sus efectos; y la ciencia del discurso o lógica se ocupa de los discursos y de sus efectos, pues se llama lógica por logos que significa discurso». 
21. Asimismo, en su comentario a este tratado, Boecio ${ }^{11}$ dice que las voces que significan se consideran de un modo en cuanto se imponen ${ }^{12}$ con el fin de significar y se consideran de otro en cuanto se hallan en ellas, en tanto significan unas propiedades causadas por el intelecto. La lógica las considera según el primer modo; la gramática, según el segundo modo ${ }^{13}$. Y así, el sujeto primero de este libro es la voz que significa el concepto simple (vox significans conceptum simplicem), y en grado sumo, las diez voces que significan los diez géneros porque a estas diez se reducen todas las otras voces.

22. Contra esto se opone lo que afirma Aristóteles en el capítulo sobre la relación, "conocido uno de los correlatos definidamente, se conoce también el otro"14. Por lo tanto, si el lógico considera la voz en cuanto

11 Boecio, In Categorias Aristotelis, I (PL 64, 159 C): «Ergo prima positio nominis secundum significationem vocabuli facta est, secunda vero secundum figuram: et est prima positio, ut nomina rebus imponerentur, secunda vero ut alii nominibus ipsa nomina designarentur». «Por tanto, la primera posición de un nombre ha sido hecha según el significado del vocablo; por su parte, la segunda posición ha sido echa según su figura. Hay una primera imposición con el fin de que unos nombres fueran impuestos a las cosas y una segunda imposición con el fin de que esos mismos nombres fueran designados por otros nombres». Ver la siguiente nota.

$12 \mathrm{La}$ «imposición» es el acto por el cual se le asigna o se le da un nombre a una cosa o a otro nombre. Así, en la nota anterior, según Boecio, con la primera imposición se asigna un nombre a una cosa para significarla y con la segunda imposición se asigna un nombre a otro nombre atendiendo a su función gramatical. Por ejemplo, a un hombre concreto se le impone el nombre «hombre» y al término «hombre» se le impone el nombre «sustantivo». En el pensamiento medieval, la imposición es un elemento recurrente y fundamental de la reflexión filosófica sobre el significado. Sobre el concepto de imposición, véase: Ashworth, 1991, p. 45. Ver también las observaciones fundamentales de S. Ebbesen (1979): «The Parisian masters also tend to evoke the picture of some definite person, the 'impositor' who assigns the ratio and modus significandi to the word on some definite occasion. However, whether the imposition is envisaged as a historical event or not, the essential fact about it is that it has binding effects. Words signify what and in the way they were imponed to signify» (p. 47). Para una discusión más amplia: Marmo, 1994, pp. 56-63. (N. del T.)

13 Aunque esto es lo que afirma el texto de la edición crítica, el sentido de toda la cuestión apunta a lo contrario: la lógica se ocupa de las voces en cuanto en ellas se hallan unas propiedades causadas por el intelecto y la gramática se ocupa de ellas en cuanto se imponen para significar. Los manuscritos $\mathrm{N}$ y R señalan esa inversión. Véase el aparato crítico de este pasaje Duns Scotus, In Praed., q. 1, n. 21, línea 1 (OPh, I, 255). (N. del T.)

14 Aristóteles, Praedicamenta, 7, 8b 13-15 (AL, I², 63). Auctoritates Aristotelis (ed. J. Hamesse, 303, n. 28): «Quicumque definitive noverit unum correlativorum, definitive nosciturus est et reliquum». «Quienquiera conoce de modo determinado un correlativo, conoce de modo determinado el otro correlativo». 
significa la cosa, es necesario que el lógico conozca la cosa definidamente. Lo que parece inconveniente.

23. Asimismo, toda voz significante en el género de la voz significante es singular; por lo tanto, no hay ningún orden entre unas y otras. Por lo tanto, no se reducen en mayor medida otras voces significativas a estas [las categorías], que estas a otras voces significativas.

24. En respuesta al primero de estos argumentos (n. 22) puede decirse que la voz no es, en primer lugar, signo de la cosa sino del concepto, la cual ${ }^{15}$ el lógico considera necesariamente no en tanto primer sujeto, sino con miras al (propter) conocimiento del primer sujeto.

25. Contra esta argumento: el concepto es signo posterior de la cosa; por lo tanto, aún se sigue que es necesario que la cosa sea conocida.

26. Este argumento no solo se opone a la posición de Boecio, sino también a quienes afirman que la lógica trata de los conceptos. Por lo tanto, puede decirse que no es necesario para conocer uno de los relativos conocer el otro en cuanto a todo lo que en él se halla en sí (ad omnia quae sibi insunt in se), sino únicamente en cuanto a todo aquello que se halla en él y se refiere al otro relativo. De este modo, no es inconveniente que en lógica la cosa sea conocida en cuanto es significada por el concepto.

27. En respuesta al segundo argumento (n. 23) puede decirse que aunque en el género de la voz no haya algún orden entre las voces que significan, en cuanto significan conceptos hay, no obstante, un orden entre ellas, así como toda proposición en el género de las proposiciones es singular; sin embargo "una es singular, otra es universal" ${ }^{16}$ en razón de lo significado por el concepto.

15 Modifico la lección quem de la edición crítica, por la lección quam del manuscrito D. La lección quem hace del concepto un objeto conocido en función del conocimiento del sujeto principal que sería al voz. Sin embargo, toda la cuestión está construida para demostrar que la voz es un objeto conocido en función del conocimiento del sujeto principal de la lógica que es el concepto. Al respecto, ver el aparato crítico de este pasaje Duns Scotus, In Praed., q. 1, n. 24, línea 15 (OPh, I, 255). (N. del T.)

16 Aristóteles, De Interpretatione, 7, 17a 38-39 (AL, II' , 9-10). 


\section{Q. 2: ¿El libro de las Categorias se ocupa de las diez categorías como de su sujeto?}

SE PREgUNTA Si ESTE LIBRO SE OCUPA de las diez categorías como de su sujeto (subiectum).

\section{1-3 ARGUMENTOS EN CONTRA}

1. Al parecer, no.

Porque "saber es conocer la cosa por la causa" según Aristóteles en los Segundos Analíticos ${ }^{17}$, por lo tanto, todo cognoscible tiene una causa. Estas diez no tienen causa; por lo tanto, de ellas no hay ciencia. Prueba de la menor: "la causa es naturalmente anterior a aquello de lo que es causa" ${ }^{18}$ pero, puesto que estas son primeras, no hay nada naturalmente anterior a ellas; por lo tanto, etc.

2. Asimismo, "a una ciencia corresponde un sujeto (unum subietum)"19; estas diez no son un único sujeto (unum subiectum), porque no son un único definible. Por lo tanto, puesto que esta es una única ciencia, no se ocupará de estas diez.

3. Asimismo, hay una ciencia real que se ocupa de ellas, por lo tanto, no lo hace la lógica. La implicación es evidente a partir del tercer libro de Aristóteles Sobre el alma: "las ciencias se dividen según las cosas"20, pero la lógica es diversa a toda ciencia real; por lo tanto, su sujeto es diverso al sujeto de cualquier ciencia real. Prueba del antecedente: tanto porque el

17 Aristóteles, Analytica Posteriora, I (A), 2, 71b 10-12 (AL, IV 4, 7). Auctoritates Aristotelis (ed. J. Hamesse, 311, n. 8): «Scire est causam rei cognoscere et quoniam illius est causa, et non contingit aliter se habere». «Saber consiste en conocer la causa de una cosa y que es su causa y que no ocurre que sea de otro modo».

18 Ver: Duns Scotus, Theoremata, Pars 8, Conclusio 2, n. 10 (OPh, II, 662): «Causa est naturaliter prior causato». «Una causa es naturalmente anterior a lo causado».

19 Aristóteles, Analytica Posteriora, I (A), 28, 87a 38 (AL, IV , 60): «Una autem scientia est quae est unius generis». «Es una la ciencia de un solo género» (Trad. del griego, Candel Sanmartín, p. 383).

20 Aristóteles, De Anima, III (C), 8, 431b 24-25 (ed. R.-A. Gauthier, 235): «Secatur igitur sciencia et sensus in res». «Por lo tanto, la ciencia y la sensación se dividen en las cosas» Auctoritates Aristotelis (ed. J. Hamesse, 188, n. 162): «Scientiae secantur quemadmodum res de quibus sunt scientiae». «Las ciencias se dividen como las cosas de las que son ciencias». 
metafísico se ocupa de ellas, como es manifiesto en los libros V y VII de la Metafisica ${ }^{21}$, como porque estas son cosas de primera intención (res primae intentionis) — prueba: porque es imposible que algo de segunda intención se predique por sí de una cosa de primera intención, pero estos diez géneros generalísimos se predican por sí de cosas de primera intención - en efecto esta proposición es verdadera: por sí "el hombre es una substancia" ("homo est substantia"); por lo tanto, toda ciencia que se ocupe de ellas es una ciencia real.

\section{ARGUMENTO A FAVOR}

4. En contra está Aristóteles. Aquí determina sobre los diez más generales (de decem generalissimis); y de modo semejante, este libro se titula Sobre las categorias (liber Praedicamentorum).

\section{5-9 ESTADO DE LA CUESTIÓN}

5. Sobre la cuestión se dice ${ }^{22}$ que las diez categorías pueden considerarse de dos maneras: de un modo, en tanto son entes, y de otro, en tanto son consideradas por la razón o en cuanto alguna propiedad causada por el intelecto se les atribuye.

6. El metafísico las considera del primer modo. En efecto, su sujeto primero es el ente en tanto ente (ens in quantum ens).

7. Aquí, [en el libro de las Categorías], son consideradas del segundo modo. En efecto, se muestran (ostenduntur) las propiedades que son inherentes a ellas en tanto son los géneros generalísimos (generalissima), como a propósito

21 Aristóteles, Metaphysica, V ( $\Delta$ ), 7, 1017a 22-34 (AL, XXV², 94-95) y VII (Z), 1, 1028a 10-20 (AL, $\left.\mathrm{XXV}^{2}, 123\right)$.

22 Pedro de Alvernia, Praed. q. 3 (CIMAGL, 55, p. 11): «...de praedicamentis possumus loqui dupliciter: aut secundum sui entitatem et essentiam, et sic sunt de consideratione ipsius metaphysici; aut secundum quod in ipsis fundantur secundae intentiones et sic ea logicus considerat». «Podemos hablar de las categorías de dos maneras: según su entidad y esencia, y de ese modo son consideradas por el metafísico; o en tanto en ellas se fundan las segundas intenciones, y de ese modo las considera el lógico». 
de la substancia: "predicarse unívocamente"23 y "no ser en sujeto"24 y "parecer significar una entidad individual" ${ }^{\prime 2}$. De modo semejante se determina sobre los otros géneros según tal razón, puesto que en cuanto tales se dividen en sus especies, y estas ulteriormente en otras, y nada hay sobre ellas que descienda en ellas por división. Así es evidente a propósito de ellas, en cuanto son los géneros generalísimos (generalissima), que poseen estas propiedades: "dividirse en especies" ${ }^{\text {"6 }}$, "tener muchas especies subalternas" ${ }^{\text {27 }}$ y "no tener un género superior"28. Y si aquí [en el libro de las Categorías] se determina sobre algunas otras [propiedades] que se encuentran en estos géneros más generales, en tanto son entes, esto no ocurre principalmente en orden al propósito [del libro], sino para la mayor manifestación de aquellos, en cuanto a los predicados intencionales.

8. Sin embargo, puesto que estas diez no son el sujeto de una única ciencia real, a saber, de la metafísica, sino en cuanto hay en ellas un principio al cual las otras son atribuidas, como se encuentra en la Metafísica $\mathrm{IV}^{29} \mathrm{y}$, en cuanto son consideradas por la razón, no hay ningún principio al cual sean atribuídas, ¿̇cómo constituyen un único sujeto (unum subiectum)?

9. Es necesario decir que es mayor la unidad de ellas en alguna propiedad causada por el intelecto que en cuanto son entes. Y así, puesto que esta ciencia no es una por una unidad de analogía, es necesario asignar algo intencional (aliquid intentionale) que sea común a ellas y sujeto primero, puesto que el lógico considera por sí unicamente algo de tal tipo.

23 Aristóteles, Praedicamenta, c. 5, 3a 34 (AL, $\left.\mathrm{I}^{2}, 51\right)$.

24 Aristóteles, Praedicamenta, c. 5, 3a 7 (AL, I', 50).

25 Aristóteles, Praedicamenta, c. 5, $3 \mathrm{~b} 10$ (AL, I $\left.{ }^{2}, 525\right)$.

26 Porfirio, Liber praedicabilium (Isagoge), c. 'De specie', II,14 (AL, I', 13).

27 Porfirio, Liber praedicabilium (Isagoge), c. 'De specie', II, 14 (AL, I' ${ }^{6}, 13$ ).

28 Porfirio, Liber praedicabilium (Isagoge), c. 'De specie', II,5 (AL, I' 9 , 9).

29 Aristóteles, Metaphysica, IV (Г), 2, 1003b 16-17 (AL, XXV², 61-62). 


\section{0-18 OTRA OPINIÓN}

10. Sin embargo, algunos ${ }^{30}$ afirman que [el sujeto de este libro] es "un ente no-complejo decible y ordenable en un género" ${ }^{31}$.

11. Teniendo en cuenta lo que se ha dicho anterioremente, contra esto último puede argumentarse así: el ente no conviene unívocamente a todo ente fuera del alma ${ }^{32}$; por lo tanto, con mayor razón no es unívoco al ente fuera del alma y al ente causado por la consideración del intelecto, pues estos dos difieren aún más. Por lo tanto, , aquí se toma “ente" por el ente fuera del alma o por el ente de razón.

12. Si se toma por "ente" el ente fuera del alma, de allí se siguen dos inconvenientes, a saber, en primer lugar, que lo que se propone como sujeto no es unívoco a las diez categorías que aquí se consideran, siendo lo opuesto lo que se trata de sostener. En segundo lugar, que el sujeto aquí sería el ente por accidente, pues estaría compuesto de una cosa de primera intención y de una cosa de segunda intención, las cuales no constituyen un ente por sí. Según Aristóteles, en la Metafísica IV, del ente por accidente no hay ciencia ${ }^{33}$.

$30 \mathrm{Al}$ respecto: Nicolaus Parisiensis, Praed. (cod. lat. Monacen. SB Clm. 14460, f. 42ra): «Et quia una est scientia ab unitate subiecti, non determinat de his in quantum decem sunt, sed in quantum inveniuntur in hoc communi quod est dicibile incomplexum ordinabile». «Y puesto que es una única ciencia debido a la unidad de su sujeto, no se tratan [las categorías] en cuanto son diez, sino en cuanto confluyen en ese elemento común que es un no-complejo decible ordenable». Ioannes de Saccavilla, Praed. (cod. Cantabrig. Domus Petri 205, f. 10av): « ...et est quaedam celebris opinio quae ponit quod ens incomplexum dicibile ordinatum in genere est hic subiectum». «...y hay una celebro opinión que establece que el ente no-complejo decible ordenado en un género es aquí el sujeto». Citados en la edición crítica, Duns Scotus, In Praed., q. 2 n. 10 (OPh, I, 260), nota 15.

31 Esta parece haber sido una opinión corriente en el siglo xIII, para responder a la pregunta por la unidad lógica de las categorías, desde la consideración de la lógica como scientia sermocinalis. Subrayemos por lo tanto, siguiendo la crítica de Escoto, que esta opinión se mantiene en el terreno del lenguaje, del discurso, de lo decible. Uno de los esfuerzos de la filosofía de la lógica escotista consiste precisamente en abandonar ese terreno en favor de un tratamiento puramente intencional o conceptual de las categorías y de la lógica. Véase:. Pini, 2002, pp. 154-159; Newton, 2008, pp. 233-234; Salinas, 2015 y 2016. En esta última referencia, en anexo, se ofrece la traducción de las cuestiones 1 y 2 del comentario de Escoto a la Isagoge de Porfirio: Duns Scotus, In Porph., qq. 1-3 (OPh, I, 3-20). (N. del T.)

32 Cfr. Duns Scotus, In Praed., q. 4 n. 27 y 38 (OPh, I, 280-281 y 285).

33 Aristóteles, Metaphysica, VI (E), 2, 1026b 24-26 (AL, XXV², 119). 
13. Si se toma por "ente" el ente de razón, se sigue una redundancia $(\text { nugatio })^{34}$, pues los otros que se adicionan (alia addita) incluyen al ente así tomado, y así ocurre la redundancia.

14. Asimismo, o se toma "decible" por aquello significable por el discurso (per sermonem), y ya se mostró en la solución de la cuestión precedente (q. 1, nn. 11 y 15) que esto ocurre con el sujeto de este libro; o se toma "decible" por lo predicable, y entonces al agregar "no-complejo" se produce una redundancia, y se produce de nuevo una redundancia al agregar "ordenable en un género". Prueba de lo primero: porque ni la proposición ni algo complejo se predican en cuanto complejos. Prueba de lo segundo: "predicable" incluye "ordenable en un género", o por el contrario, al ser algo predicable, como aquí lo afirma Aristóteles, se ordena a otro según lo inferior o lo superior.

15. Con respecto a esto último se dice que los individuos son ordenables en un género; sin embargo, no se dice que son predicables. Con todo, los predicables generalísimos no se ordenan en un género. Por lo tanto, ninguno de ellos incluye a los otros.

16. En contra: entonces "el ente no-complejo decible y ordenable en un género" no conviene a los géneros generalísimos, de los cuales se trata aquí en grado sumo; por lo tanto, aquel no es aquí el sujeto.

17. Si se pusiera por sujeto solo "ente no-complejo" o solo "ente decible" o solo "ente ordenable en un género", contra cualquiera de estas alternativas se tiene la primera razón (nn. 11 y 16) expuesta contra la anterior posición y contra la primera posición (nn. 11-14).

34 La nugatio consiste en la repetición innecesaria de un predicado. Innecesaria, porque la duplicación de un predicado es lógicamente irrelevante, no agrega una determinación suplementaria a propósito del sujeto del que se predica algo. En este caso, cada uno de los predicados incluye la propiedad "ente de razón", de tal modo que al predicarse simultáneamente del mismo sujeto, producen una nugatio múltiple. Al respecto, véase: Pini, 2002, p. 161. (N. del T.) 
18. Si se pusiera por sujeto solo "predicable", este es lo mismo que universal ${ }^{35}$. Por lo tanto, el sujeto de este libro y del libro de Porfirio ${ }^{36}$ sería el mismo. Y esto es inconveniente y excede las diez categorías.

\section{9-27 SOLUCIÓN DE ESCOTO}

19. Por lo tanto, puede decirse que aquí [en el libro de las Categorias] se consideran las diez categorias (praedicamentis) en cuanto se atribuye a ellas algo causado por la razón, porque de otro modo no pueden ser consideradas por el lógico. Y de este modo, no solo tienen una unidad de analogía, sino también una unidad de univocación. Y eso unívoco en ellas, de este modo, es algo intencional, que es aquí [en el libro de las Categorías] el sujeto primero. Esto puede llamarse 'categoría' (praedicamentum) o género 'generalísimo' (generalissimum), puesto que todas las propiedades que aquí se determinan por sí sobre estas diez, se determinan en cuanto ellas tienen la razón de género generalísimo o categoría.

20. En contra: entonces, aquí [en el libro de las Categorías] solo se determina por accidente sobre la substancia, la cantidad y las demás categorías, pues se determina sobre ellas únicamente en tanto algo se halla (inest) en ellas por accidente, a saber, algo intencional, pues nada de tal índole puede hallarse (inesse) en ellas por sí.

21. Asimismo, aquí [en el libro de las Categorías] no se demuestra ninguna propiedad de una categoría o género generalísimo según su razón propia, por lo tanto eso, [el rasgo intencional], no es su sujeto.

22. Asimismo, aquí [en el libro de las Categorías] el sujeto no conviene a todo concepto formado por el primer acto de la razón, como en el tratado Sobre la interpretación [el sujeto] conviene a todo concepto formado por el acto segundo [de la razón]. Esto parece inconveniente, pues así como aquel libro parece ocuparse del concepto no-complejo, este parece ocuparse del complejo.

35 Aristóteles, De Interpretatione, I, 7, 17a 39-40 (AL, II $\left.{ }^{2}, 45\right)$.

36 Duns Scotus, In Porph., qq. 7-8 n. 24 (OPh, I, 40): «Ad primam quaestionem dicendum quod universal est subiectum huius scientiae». «Hay que responder a la primera cuestión que el universal es el sujeto de esta ciencia [de los predicables]». 
23. Asimismo, puesto que el género generalísmo o categoría está contenido bajo el universal, de allí se sigue que esta ciencia es subalterna a [la ciencia tratada en] el libro de Porfirio, pues así como un sujeto se relaciona con otro sujeto, así una ciencia con otra ciencia. Pero esto parece inconveniente.

24. Al primero de estos argumentos (n. 20) digo que no es inconveniente que el lógico únicamente considere las categorías por accidente, pues el metafísico las considera por sí.

25. Al segundo argumento (n. 21) digo que en cuanto aquí [en el libro de las Categorias] se determina algo intencional unívoco sobre la substancia y la cantidad, en cuanto poseen la razón de género generalísimo, por ello mismo, aquel [intencional unívoco] se dice primeramente del género generalísimo. Por ejemplo, "dividirse en especies" y "no tener género superior", y "predicarse unívocamente"; [intenciones unívocas] que se muestran (ostenditur) de la substancia y se suponen conocidas a propósito de las otras [categorías]. Por tanto, en tanto algo unívoco se muestre de muchos sujetos no primeros (de multis subiectis non primis), se muestra de su sujeto primero.

26. Al tercer argumento (n.22) puede decirse que la enunciación (enunciatio) es el sujeto primero del tratado Sobre la interpretación ${ }^{37}$. Esta no se dice por una predicación formal de todo concepto formado por el segundo acto de la razón, sino que los otros se reducen al mismo, como ocurre con la oración imperativa. Así, todo concepto simple se reduce a alguna de las categorías.

27. Al cuarto argumento (n. 23) puede decirse que aunque un sujeto se encuentre bajo otro sujeto, una de estas ciencias no toma sus principios de la otra. Y por lo tanto, falta una de las condiciones que se requieren para la subalternación de las ciencias ${ }^{38}$.

37 Duns Scotus, In Peri herm., I, q. 1 n. 2 (OPh, II, 44): «Ergo enuntiatio potest hic convenienter poni subiectum, et hoc enuntiatio in mente, quia illa causatur ex secunda operatione intellectus». «Por lo tanto aquí puede establecerse convenientemente como sujeto el enunciado, esto es, el enunciado en la mente, puesto que él es causado por la segunda operación del intelecto».

38 Duns Scotus, In Met., I, q. 9 n. 40 (OPh, III, 175): «Condicio una subalternatae scientiae est quod subiectum suum sit sub subiecto subalternantis. Alia est quod scit 'quia', ubi superior scit 'propter quid', et a superiori accipit sua principia ad probandum conclusiones». «Una condición de una 


\section{8-30 RESPUESTAS A LOS ARGUMENTOS PRINCIPALES}

28. Con respecto al primer argumento principal (n. 1), digo que aunque en sí ellas no tengan una causa, respecto a sus propiedades tienen, no obstante, una causa; principalmente con respecto a las propiedades intencionales que les pertenecen (quae insunt eis) en cuanto son consideradas por la razón. Y es en sí verdadero decir que "nada es anterior a ellas naturalmente"; sin embargo, con respecto a la inherencia en ellas de sus propiedades intencionales puede haber algo naturalemente anterior.

29. Con respecto al segundo argumento (n. 2), es evidente que el sujeto primero (primum subiectum) aquí es algo unívoco a estas diez, como 'categoría' ('praedicamentum').

30. Con respecto al tercer argumento (n. 3), es evidente que lo que el metafísico considera por sí, aquí es considerado accidentalmente (per accidens), a saber porque es considerado por sí algo intencional aplicable a ellas.

\section{Q. 3: ¿Algún predicado intencional es unívoco a las diez categorías?}

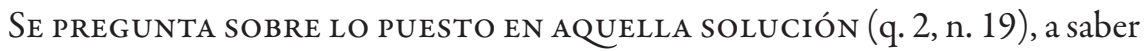
si algo es unívoco a estos géneros generalísimos y, en primer lugar, si algún predicado intencional es unívoco a ellos.

\section{1-4 ARGUMENTOS EN CONTRA}

1. Parece que no.

Porque si sí, entonces aquel sería anterior y más común que las categorías, y así, las categorías no serían géneros generalísimos y géneros primeros. Esto va contra Boecio (q. 1, n. 1).

2. Asimismo, si algo fuera unívoco a ellas, puesto que ellas son diversas entre sí, serían 'entes con algo idéntico; por lo tanto, diferencias' ('aliquididem entia; ergo differentia'). La consecuencia es evidente a partir de la

ciencia subalternada es que su sujeto se encuentre bajo el sujeto de una ciencia subalternante. Otra condición es que la ciencia subalternada conozca por el efecto, allí donde la ciencia superior conoce por la causa; y que tome de la superior sus principios para probar sus conclusiones». 
definición de las realidades diferentes del libro V de la Metafísica ${ }^{39}$. El consecuente es falso porque las categorías son diversas por sí y no son diferencias, ya que entonces serían especies.

3. Asimismo, la intención es causada por la cosa, por lo tanto la unidad de la intencion lo es por la unidad de la cosa; sin embargo, ninguna cosa conviene unívocamente a las categorías, y por lo tanto, tampoco ninguna intención. La primera proposición es evidente: en efecto, aquello que es debido al intelecto y no a la cosa es una ficción (figmentum), ninguna intención es una ficción.

4. Asimismo, ningún unívoco es denominativo; sin embargo, el predicado intencional únicamente se dice denominativamente de aquellas cosas que son cosas de intención primera. Por lo tanto, ningún predicado intencional es unívoco a estas. Prueba de la mayor: tanto porque aquí [en el tratado de las Categorías] el unívoco se distingue del denominativo como del equívoco; como porque, más abajo, dice Aristóteles en el capítulo sobre la substancia ${ }^{40}$, que "algunos se predican según el nombre y no según la razón del nombre”, como los [términos] concretos o denominativos, y lo ejemplifica con lo blanco.

\section{5-7 ARGUMENTOS A FAVOR}

5. A favor de la solución opuesta: algo intencional se dice de las diez categorías según el mismo nombre y la misma razón, por lo tanto, unívocamente. La consecuencia es evidente a partir de la definición de los unívocos $^{41}$. Prueba del antecedente: la substancia es un género, la cantidad es un género, etcétera.

39 Aristóteles distingue entre las realidades diferentes (que comparten un elemento común) y las realidades diversas que no tienen nada en común. Las categorías deben ser pues diversas y no diferentes en tanto son géneros primerísimos y generalísimos. Aristóteles, Metaphysica, V $(\Delta), 9$, 1018a 12-13 (AL, $\left.\mathrm{XXV}^{2}, 96\right)$ : «Differentia vero dicuntur quaecumque diversa sunt idem-aliquid entia, et non solum numero sed specie aut genere aut proportione». «Se dice que son «diferentes» aquellas cosas que son diversas, pero siendo lo mismo en algún aspecto, sólo que no numéricamente, sino según la especie o según el género o por analogía» (trad. del griego Calvo Martínez, p. 228). (N. del T.)

40 Aristóteles, Praedicamenta, 5, 2a 29-34 (AL, I²49).

41 Aristóteles, Praedicamenta, 1, 1a 6-7 (AL, I²47). 
6. "Substancia" se predica esencialmente de muchas cosas que difieren en especie, así como "cantidad". Esto es así porque "género" se predica de ellas según el nombre y la definición ${ }^{42}$. Así puede argumentarse a propósito de muchas intenciones inherentes a las categorías o contenidas bajo ellas, como "especie" para el caso del hombre y la blancura.

7. Asimismo, la sola diversidad en una materia accidental no diversifica aquello de lo que es especie, pues la diferencia en la especie es una diferencia formal ${ }^{43}$. Sin embargo, una intención, aplicada a una cosa de un género y a una de otro, tiene una diferencia por accidente con respecto a la materia. Por lo tanto, no difiere en la especie en razón a hallarse en estas [las categorías]. Por lo tanto, a causa de esto no se elimina la univocación, pues lo que no elimina la unidad según la especie, no elimina la univocación. La primera proposición es evidente, pues el círculo áureo y el círculo broncíneo no difieren en especie. Y es también manifiesto por la razón, pues tal diferencia, con aquello a lo cual se agrega, solo produce un ente por accidente, que no es por naturaleza especie de un género. La menor también es manifiesta, pues ninguna intención se halla (inest) por sí en una cosa de primera intención, como se mostró antes ${ }^{44}$. Sin embargo, la sola diversidad aquí y allá se produce con respecto a las cosas de primera intención y, por lo tanto, solo con respecto a una materia accidental.

42 Porfirio, Liber praedicabilium (Isagoge), c. 'De genere', I,5 (AL, I' ${ }^{6}, 6-7$ )

43 Ver: Tomás de Aquino, SCG, II, c. 80-81, ad 2 (ed. Leonina XIII, 505a): «Non enim qualibet formarum diversitas facit diversitatem secundum speciem, sed solum illa quae est secundum principia formalia vel secundum diversam rationem formae». «Porque no es cualquier diversidad de formas la que da origen a la diversidad específica, sino sólo aquella que es según los principios formales o según una diversa razón formal» (Trad. del latín Robles Carcedo y Robles Sierra, p. 580).

44 Véase: Duns Scotus, In Porph., q. 9-11, n. 28 (OPh, I, 50): «Impossibile est autem aliquam rem secundae intentionis definire rem primae intentionis, quia tunc illa res secundum suam essentiam partim esset a natura et partim ab intellectu, et ita a diversis causis non ordinatis; quare non esset unum essentialiter. Igitur impossibile est aliquam intentionem primo modo per se praedicari de re». «Es pues imposible que alguna cosa de segunda intención defina una cosa de primera intención, porque entonces esta cosa, según su esencia, sería en parte por naturaleza y en parte por el intelecto, y entonces sería a partir de causas diversas no ordenadas; por lo cual no sería esencialmente una. Por lo tanto, es imposible que alguna intención se predique por sí en el primer modo de una cosa». Duns Scotus, In Met., V, q. 4 n. 27 (OPh, III, 444): «Quia ens secundae intentionis non definiturper ens primae intentionis... ». «Porque un ente de segunda intención no se define por un ente de primera intención...». 


\section{SOLUCIÓN}

8. Hay que responder a la cuestión que algo intencional unívoco puede aplicarse a las cosas de todos los géneros, porque toda diversidad en las cosas de primera intención, entre ellas, no impide que ellas puedan concebirse por el intelecto según el mismo modo de ser concebidas (per eundem modum concipiendi). Las intenciones se atribuyen a las categorías en cuanto son concebidas por el intelecto, y por ello las intenciones de la misma especie pueden atriburise a diversas cosas.

\section{9-14 RESPUESTAS A LOS ARGUMENTOS PRINCIPALES}

9. En respuesta al primer argumento (n. 1) puede decirse que [las categorías] son primeras y géneros comunísimos de las cosas y no de las intenciones.

10. Del mismo modo con respecto al segundo argumento (n. 2), que no son diferentes, pues no son el mismo ser en algún respecto (aliquid-idem entia), es decir alguna cosa.

11. Otro modo de responder a una y otra objeción (nn. 1-2): aunque sean los géneros generalísimos y primeros, algo idéntico puede hallarse (aliquid-idem inesse), , en todos ellos denominativamente. Esto no debe decirse anterior y más común que ellos, a no ser que se diga de ellos esencialmente.

12. También en respuesta al segundo argumento (n. 2), [puede decirse] que [las categorías] no son el mismo ser en algún respecto (aliquid-ideo), y por ello no se sigue que sean diferentes. Esto es de algún modo manifiesto donde menos parece, a saber, en los accidentes reales, pues "blanco", que significa algo único, se dice de la superficie y del hombre, que pertenecen a dos géneros. Pero esto no es en absoluto semejante: en efecto, un accidente real solo tiene algo único en virtud de un sujeto próximo, de tal modo que nada más se halla (inest) en ese sujeto, salvo por su naturaleza. Es por ello que otro puede ser su sujeto solamente por accidente, mediante un sujeto primero. Sin embargo, el accidente intencional puede hallarse de modo igualmente inmediato (aeque primo inesse) en cosas de todos los géneros, y en ninguna por intermedio de otro. 
13. Al tercer argumento (n. 3) respondo que la cosa no es la causa total de la intención, sino solo la ocasión, a saber, en cuanto mueve al intelecto para que considere en acto, y el intelecto es la causa principal. Por lo tanto, basta una unidad menor en la cosa que en la intención, porque basta que el intelecto sea movido por algo extrínseco para causar muchas [intenciones] por su consideración, las cuales no corresponden a algo en la cosa. Como la blancura, al existir, es en cierto sentido "algo que permanece por sí" (per se stans), o el movimiento en cierto sentido posee el modo del hábito. En efecto, el intelecto atribuye al uno y al otro, de manera semejante, el modo del hábito y el modo de algo que permanece por sí, como a un hombre. Y uno y otro son, considerados en absoluto (simpliciter), un nombre. Sin embargo, hay algo en uno y otro que corresponde a aquel modo, pero no realmente como una intención causada por el intelecto, esto es, movido de modo extrínseco. De modo semejante, el intelecto al considerar, por aquella única especie, puede reflexionar miles de veces sobre su propia operación considerando, y cada consideración es algo, aunque no haya nada extrínseco que le corresponda, salvo el primer objeto (primum obiectum) tomado como ocasión, en cuanto él mueve el intelecto a la consideración. De esto se ha hablado en el libro de Porfirio ${ }^{45}$.

14. Al cuarto argumento (n. 4) digo que es distinto decir "algo unívoco predicado de muchos" y "hay un predicado unívoco de muchos". El denominativo es unívoco en el primer modo, no en el segundo, como muestra la razón. Es por ello que concedo la conclusión según la cual ningún predicado intencional es un predicado unívoco de las cosas de primera intención, pero algo intencional unívoco en sí se predica de estas [las categorías] no unívocamente. Pero de esto se hablará más en lo que sigue ${ }^{46}$.

45 Ver: Duns Scotus, In Porph., q. 1 n. 12 (OPh, I, 6); q. 5 n. 4 (OPh, I, 27-28).

46 Ver: Duns Scotus, In Praed., q. 4 nn. 26 y 37 (OPh, I, 280 y 285). 
Bibliografía

\section{FUENTES PRIMARIAS}

Aristoteles Latinus, Categoriae vel praedicamenta. Translatio Boethii, editio composita translatio Guillelmi de Moerbeka, lemmata e Simplicii commentario decerpta, Pseudo-Augustini paraphrasis Themistiana, ed. L. Minio-Paluello, «Aristoteles Latinus, I 1-5», Brujas-París, Desclée De Brouwer, 1961.

Aristoteles Latinus, De interpretatione vel Periermenias. Translatio Boethii, ed. L. Minio-Paluello; Translatio Guillelmi de Moerbeka, ed. G. Verbeke, rev. L. Minio-Paluello, «Aristoteles Latinus, II 1-2», Brujas-París, Desclée De Brouwer, 1965.

Aristoteles Latinus, Analytica posteriora. Translationes Iacobi, Anonymi sive 'Ioannis, Gerardi et Recensio Guillelmi de Moerbeka, eds. L. Minio-Paluello y B. G. Dod, «Aristoteles Latinus, IV 1-4», Brujas-París, Desclée De Brouwer, 1968. Aristoteles Latinus, Metaphysica, lib. I-X, XII-XIV. Translatio Anonyma sive 'Media', ed. G. Vuillemin-Diem, «Aristoteles Latinus, XXV 2», Leiden, Brill, 1976.

Aristoteles Latinus, De Anima, ed. R.-A. Gauthier, en Tomás de Aquino, Sententia libri De Anima, ed. R.-A. Gauthier, in Opera omnia t. XLV.1, 2a ed., Roma-París, Commissio Leonina-J. Vrin, 1984.

Aristóteles, Tratados de lógica (Órganon), Vol. I: Categorías, Tópicos, Sobre las Refutaciones Sofísticas, Introducción, traducción y notas de Miguel Candel Sanmartín, Madrid, Biblioteca Clásica Gredos, 1982.

Aristóteles, Tratados de lógica (Órganon), Vol. II: Sobre la Interpretación, Analíticos Primeros, Analíticos Segundos, Introducción, traducción y notas de Miguel Candel Sanmartín, Madrid, Biblioteca Clásica Gredos, 1988.

Aristóteles, Metafísica, Introducción, traducción y notas de Tomás Calvo Martínez, Madrid, Biblioteca Clásica Gredos, 1998.

Auctoritates Aristotelis. Un florilège médiéval : étude historique et édition critique, ed. J. Hamesse, «Philosophes Médiévaux, XviI», Lovaina-París, Publications Universitaires-Béatrice Nauwelaerts, 1974. 
Avicenna, Liber de philosophia prima sive Scientia divina I-IV, ed. S. Van Riet, introducción doctrinal G. Verbeke, «Avicenna Latinus», Lovaina-Leiden, Peeters-Brill, 1977.

Boecio, In Categorias Aristotelis libri quatuor, ed. J.-P. Migne, «Patrologia Latina, 64», París, 1847.

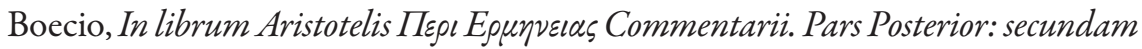
editionem et indices continens, ed. C. Meiser, Leipzig, Teubner, 1880.

Ioannes de Saccavilla, Supra praedicamenta, cod. Cantabrig. Domus Petri 205, ff. 10va-20va.

Ioannis Duns Scoti, Quaestiones super libros metaphysicorum Aristotelis, en R. Andrews et al. (eds.), Opera philosophica tomos III-IV, St. Bonaventure (NY): The Franciscan Institute, 1997.

Ioannis Duns Scoti, Questiones In Librum Porphyrii Isagoge et Quaestiones Super Praedicamenta Aristotelis, eds. R. Andrews et al., Opera philosophica I, St. Bonaventure (NY), The Franciscan Institute, 1999.

Ioannis Duns Scoti, Quaestiones in Libros Perihermenias Aristotelis, Quaestiones Super Librum Elenchorum Aristotelis, et Theoremata, eds. R. Andrews et al., Opera philosophica II, St. Bonaventure (NY)-Washington, The Franciscan Institute - The Catholic University of America, 2004.

John Duns Scotus, Questions on Aristotle's Categories, (trad. Inglesa Lloyd A. Newton), Washington, The Catholic University of America Press, 2014.

Nicolaus Parisiensis, In praedicamenta, cod. lat. Monacen. SB Clm. 14460, ff. 42ra-62ra.

Pedro de Alvernia, Quaestiones super Praedicamentis, ed. R. Andrews, Cabiers de l'Institut de Moyen-Age Grec et Latin, 55 (1987), p. 3-84.

Porfirio, Liber praedicabilium (Isagoge) Translatio Boethii, in Aristoteles Latinus, Categoriarum supplementa. Porphyrii Isagoge, Translatio Boethii, et Anonymi Fragmentum vulgo vocatum «Liber sex principiorum», eds. L. Minio-Paluello y B. G. Dod, «Aristoteles Latinus, I 6-7», Brujas-París, Desclée De Brouwer, 1966, p. 1-31.

Robert Kilwardby, De Ortu Scientiarum, ed. A. G. Judy, «Auctores Britannici Medii Aevi, IV», Oxford-Toronto, The British Academy-The Pontifical Institute of Mediaeval Studies, 1976. 
Tomás de Aquino, Summa contra Gentiles, ed. Commissio Leonina, in Opera omnia t. XIII, Roma, Ex Tipis Riccardi Garroni, 1918.

Tomás de Aquino, Suma contra los gentiles, I, libros 1 y 2, edición bilingüe dirigida por L. Robles Carcedo OP y A. Robles Sierra OP; introducciones de Eudaldo Forment Giralt, Madrid, Biblioteca de Autores Cristianos, 2007.

William of Sherwood, Introductiones in logicam, ed. Ch. Lohr, P. Kunze y B. Mussler, Traditio, XXXIX (1983), p. 219-299.

\section{BIBLIOGRAFÍA SECUNDARIA}

Ashworth, E.J. (1991). Signification and Modes of Signifying in ThirteenthCentury Logic: A Preface to Aquinas on Analogy. Medieval Philosophy and Theology, 1, pp. 39-67.

Ebbesen, S. (1979). The dead man is alive. Synthese, 40, pp. 43-70.

Marmo, C. (1994). Semiotica e linguaggio nella Scolastica. Parigi, Bologna, Erfurt 1270-1330. La semiotica dei Modisti, «Nuovi studi storici, 26». Roma: Instituto Storico Italiano per il Medio Evo.

Newton, Ll.A. (2008). Duns Scotus's Account of a Propter Quid Science of the Categories. Ll A. Newton (Ed.), Medieval commentaries on Aristotle's Categories, «Brill's companions to the Christian tradition, 10» (pp. 221-158). Leiden-Boston: Brill.

Pini, G. (2002). Categories and logic in Duns Scotus: An Interpretation of Aristotle's Categories in the Late Thirteenth Century, «Studien und Texte zur Geistesgeschichte des Mittelalters, 77». Leiden: Brill.

Salinas, H.H. (2015) Observaciones sobre la constitución medieval de la lógica: de scientia sermocinalis a scientia rationalis. Universitas Philosophica, 32(64), pp. 96-111.

Salinas, H.H. (2016). La determinación de la lógica como ciencia común intencional en Duns Escoto. Franciscanum, LVIII(165), pp. 51-86. 